\title{
The nature and prevalence of pain in dreams
}

\author{
Antonio L Zadra $\mathrm{PhD}^{1}$, Tore A Nielsen $\mathrm{PhD}^{1,2}$, Anne Germain $\mathrm{PhD}(\mathrm{c})^{1}$, Gilles Lavigne DMD MSc ${ }^{1,3}$, DC Donderi $\mathrm{PhD}^{4}$
}

\author{
AL Zadra, TA Nielsen, A Germain, G Lavigne, DC Donderi. \\ The nature and prevalence of pain in dreams. \\ Pain Res Manage 1998;3(3):155-161.
}

BACKGROUND: Little is known about the frequency and nature of pain in dreams. Several authors have suggested that pain may be beyond the representational capability of dreaming.

OBJECTIVE: To obtain more detailed information on the nature and prevalence of pain in a larger sample of everyday dreams collected through home logs. To examine the context within which dreamed pain occurs and to assess participants' retrospective recall of past experiences of pain in dreams.

METHOD: One hundred and eighty-five participants completed a battery of questionnaires and recorded their dreams for two consecutive weeks.

RESULTS: Retrospective responses to the questionnaire indicate that close to $50 \%$ of individuals report having experienced pain in their dreams at least once. A total of 3045 dreams were reported in the home dream logs. Eighteen of these dreams contained unambiguous references to the subject experiencing pain.

DISCUSSION: Pain sensations in dreams are reported as being realistic, localized to a specific area of the body, typically resulting from violent encounters with other characters and often accompanied by intense affect. A model is proposed to explain how sensory experiences such as pain can be produced in the dream state.

CONCLUSION: Cognitive systems that contribute to the representation of pain imagery are sometimes functional during dreaming.

Key Words: Dreams, Pain, Sensory imagery

\section{La nature et prévalence de la douleur dans les rêves}

CONTEXTE THÉORIQUE : On a très peu d'information sur la fréquence et la nature de la douleur dans les rêves. Plusieurs auteurs ont suggéré que la douleur est en deçà de la capacité représentationnelle du rêve.

BUTS : Obtenir de l'information plus détaillée sur la nature et la prévalence de la douleur dans un plus large échantillon de rêves recueillis à la maison. Examiner le contexte dans lequel la douleur se produit dans le rêve et évaluer le rappel rétrospectif d'expériences antérieures de douleur dans les rêves des participants.

MÉTHODE : Cent quatre vingt-cinq participants ont complété une batterie de questionnaires et rempli des agendas de rêves pendant deux semaines consécutives.

RÉSULTATS : Les réponses rétrospectives au questionnaire indiquent que près de $50 \%$ des individus rapportent avoir ressenti au moins une fois de la douleur dans leurs rêves. Un total de 3045 rêves ont été rapporté dans les agendas de rêves. Dix-huit de ces rêves contenaient des références indiquant que le sujet avait ressenti de la douleur. DISCUSSION : Les sensations de douleur dans les rêves sont rapportées comme étant réalistes, localisées dans un endroit spécifique du corps; elles résultaient le plus souvent de rencontres violentes avec d'autres personnages et s'accompagnaient d'un affect intense. Un modèle est proposé pour expliquer comment les expériences sensorielles comme la douleur peuvent être produites dans l'état onirique.

CONCLUSION : Les systèmes cognitifs qui contribuent à la représentation onirique de la douleur sont parfois fonctionnels durant le rêve. lthough pain has been reported to interfere with sleep
(eg, 1), little is known about the prevalence of pain in
dreams. Anecdotal accounts from the 19th century suggest
that although painful sensory stimuli can affect dream con-
tent, pain sensations are not directly incorporated into the dream narrative (2,3). Saint-Denys (4) documented several cases demonstrating extreme sensitivity to slight physical sensations while dreaming. However, he believed that dreams were completely unable to reconstitute the exact character of past pain and that, consequently, pain could not

\footnotetext{
${ }^{1}$ Hôpital du Sacré-Coeur, Centre d'étude du sommeil; ${ }^{2}$ Département de Psychiatrie, Université de Montréal; ${ }^{3}$ Faculté de Médecine Dentaire, Université de Montréal; ${ }^{4}$ Department of Psychology, McGill University, Montreal, Quebec

Correspondence and reprints: Dr Antonio Zadra, Hôpital du Sacré-Coeur, Centre d'etude du sommeil, 5400 boul Gouin Ouest, Montréal, Québec H4J 1C5. Telephone 514-338-2222 ext 3013, fax 514-338-2531, e-mail zaz@ego.psych.mcgill.ca

Received for publication March 12, 1998. Accepted August 13, 1998
} 
be experienced. In his extensive review of the scientific literature on dreams, Freud (5) cited several examples of negative dream content (eg, being scalped, being tortured on the rack or standing on intolerably hot ground) that were attributed to the effects of unpleasant sensory stimuli. Freud argued that somatic stimuli, including pain, were never the sole cause of the dream but served only to instigate specific dream images.

Contrary to these anecdotal accounts, our laboratory study found that pain sensations were mentioned in approximately $30 \%$ of rapid eye movement (REM) dream reports collected subsequent to the administration of long-duration pressure stimulation of the leg (6). We also noted that when pain occurs in dreams, it is relatively realistic and is often accompanied by intense negative affect. In a follow-up study we found that ramped pressure stimulation of the hand during REM sleep did not result in subjects reporting pain dreams (7). Both studies, however, showed that unambiguous pain dreams can occur during nonstimulated REM periods, indicating that actual painful stimuli need not be present for pain to occur in dreams.

Just as the information on the effects of painful stimuli on dream content is sparse, little is known about the nature of pain dreams that occur in the absence of any painful or uncomfortable stimuli. Case studies of individuals who repeatedly experience violent dream imagery, including images of destruction of or penetrating wounds to the body, rarely contain references to dreamed pain as part of the experience (8-12). In fact, some subjects report being surprised by the absence of pain during such dreams (eg, 12). Studies of large samples of dreams (13-15) do not mention dreamed pain. One study of 180 REM dream reports that were scored specifically for references to sensory events found no instances of pain (16). More recently, we presented a preliminary report of responses of 125 normal adults ( 28 men and 97 women) to a question about past experiences of pain in dreams, as well as response on the prevalence of pain from 2204 home dream reports (17). Fifty-nine of the 125 subjects (47.2\%) indicated that they remembered having experienced sensations of pain in their dreams at some point in their lives. Content analyses of the home dream diary reports showed that dreams containing pain were rare, occurring approximately once in every 157 dream reports and in one of 10 subjects.

The primary goal of the present study was to obtain more detailed information on the nature and prevalence of pain in a larger sample of everyday dreams collected through home logs. Secondary goals were to examine the context within which dreamed pain occurs and to assess participants' retrospective recall of past experiences of pain in dreams.

\section{PARTICIPANTS AND METHODS}

One hundred and eighty-five participants (48 men, 137 women) with a mean age of 34.6 years $(\mathrm{SD}=11.8)$ were included in the study. Mean age of men was 32.8 years $(\mathrm{SD}=11.5)$ and of women was 35.3 years $(\mathrm{SD}=11.8)$. Partici- pants were randomly selected from a larger group of 241 nonpaid volunteers (64 men, 177 women) who had been recruited through media advertisements for participation in a series of studies on the relation between dream content and measures of well-being.

After indicating interest, participants were contacted by telephone and asked to attend an information meeting. At the meeting, the research was briefly explained, the role of the participants was clarified and two research protocols were distributed. Signed consent forms were obtained from all participants. The procedures had been approved by the McGill University ethics review committee.

\section{Participants' health and retrospective accounts of pain dreams}

The first research protocol required participants to complete not only a battery of questionnaires designed to measure psychological well-being (18), but also a 68-item Sleep/Dream Questionnaire. Several items from these questionnaires were examined to assess potential pain-related conditions and their possible relationship to reported dream pain. Items included five pain-related items from the Symptoms Checklist-90Revised (SCL-90-R) (19) (ie, how much have you been bothered by: headaches; pains in heart or chest; pains in lower back; nausea or upset stomach; soreness of your muscles) and three questions from the Sleep/Dream Questionnaire (is the participant is currently under the care of a physician and if so, for what reasons?; list any current or past medical conditions; and specify any over-the-counter or prescription medications being taken).

The Sleep/Dream Questionnaire included one question that asked "Have you ever experienced sensations of physical pain in your dreams? If so, please describe". Answers to this question were tabulated and the descriptions categorized according to, first, the actions that led to the participants feeling pain and, second, the body area(s) where the dream pain was localized.

\section{Self-reporting of pain dreams in home logs}

The second protocol required participants to record all dreams that they could remember on awakening for 14 to 21 consecutive days. These dreams were written in a booklet of record sheets kept by the bed. The record sheets also prompted participants to record the theme, emotions (including intensity ratings on a five-point scale) and clarity of recollection associated with each remembered dream. Additionally, participants specified the date of the dream and the elapsed time between waking and recording the dream. Because the evaluation of pain sensations in dreams was not the focus of the original series of investigations, participants were not asked to take special note of pain sensations in their dreams.

Dream reports from the first two weeks of the home dream logs were scored by two independent judges for unambiguous references to pain experienced by the dreamer. Dream reports that described vague or unpleasant sensations (eg, feeling queasy) and reports in which pain was suggested but 
not explicitly stated (eg, "I was punched in the stomach and doubled over") were not scored as pain dreams. Dream reports were also scored for positive and negative affect according to Hall and Van de Castle's (14) Emotions Scale.

\section{RESULTS}

\section{Retrospective accounts of pain dreams}

Ninety-one of the 185 participants (49.2\%) indicated on the Sleep/Dream Questionnaire that they had experienced pain in their dreams at least once. When results were broken down by sex, 22 of 48 men (45.8\%) and 69 of 137 women (50.4\%) reported having had a pain dream at some point in their lives. This difference was not significant $\left({ }^{2}[1]=0.35, \mathrm{P}>0.05\right)$.

Table 1 presents the dreamed actions that were most frequently reported as leading to pain feelings for these 91 retrospective accounts. The category "Not specified" includes dreams in which actions related to the pain were not specified or for which the thematic content could not be determined. The thematic content for four of the five categories for which an action could be specified involve pain resulting from aggressive actions explicitly directed by an agent towards the dreamer. A fifth category (ie, being injured in an accident) involved violent and potentially aggressive acts.

Seventy-two of these 91 participants $(79.1 \%)$ wrote that the dream pain had been localized to one or more body parts for a total of 84 references to specific body areas. These references include those from nine participants who described two (or in one case, three) areas of the body in which they felt pain. A frequency distribution of body areas where dreamed pain was reported to have occurred is presented in Table 2. The three most frequently implicated regions were the abdomen, legs and head or face; these three together accounted for $49 \%$ of the references.

\section{Home dream reports}

During the two-week period of home dream recording, participants reported a mean of 16.5 dreams each $(\mathrm{SD}=7.3)$ for a total of 3045 dreams. Women reported a mean of 17.7 dreams $(\mathrm{SD}=7.5)$ and men a mean of 15.9 dreams $(\mathrm{SD}=6.8)$. This difference was nonsignificant $(\mathrm{t}[183]=0.60, \mathrm{P}>0.05)$. Sixteen participants (five men and 11 women) $(8.6 \%)$ reported a total of 18 pain dreams; two of these female participants each reported two pain dreams. There were no significant sex differences in the relative proportions of men and women who reported no pain dreams or at least one such dream during the study $\left({ }^{2}[1]=0.26, \mathrm{P}>0.05\right)$.

In 15 of the 18 pain dreams reported, an agent was described as being clearly responsible for the subject's pain. The pain sources for these 15 dreams were very sore feet because of uncomfortable shoes; having one's legs stuck under an immense steering wheel; stomach pains due to a difficult pregnancy (the subject was not in fact pregnant); having one's pubic hair ripped out by an assailant; burning skin on one's arm due to an allergic reaction; having one's arm and shoulder run over by a bus; having one's hand burned by a hot coal; being speared in the rib cage; having an assailant dig his fingers deep into the rib cage; having an assailant
TABLE 1

Actions most frequently reported on questionnaire as leading to pain in dreams $(\mathbf{n}=91)$

\begin{tabular}{lc}
\hline Action & $\mathbf{n}(\%)$ \\
\hline Being stabbed or cut & $19(20.9)$ \\
Being shot & $16(17.6)$ \\
Being injured in an accident & $10(11.0)$ \\
Being attacked by an unarmed assailant & $8(8.8)$ \\
Being bitten by an animal & $5(5.5)$ \\
No apparent reason & $4(4.4)$ \\
Not specified & $29(31.9)$ \\
Total & $91(100.1)$ \\
\hline
\end{tabular}

Percentages do not add up to 100 due to rounding

\begin{tabular}{lc} 
TABLE 2 \\
$\begin{array}{l}\text { Areas of the body where pain was localized in } \\
\text { questionnaire dream reports }(\mathbf{8 4} \text { references to specific } \\
\text { body areas) }\end{array}$ \\
\hline Body part & $\mathbf{n}(\%)$ \\
\hline Abdomen & $15(17.9)$ \\
Legs & $14(16.7)$ \\
Head or face & $12(14.3)$ \\
Back & $9(10.7)$ \\
Chest & $8(9.5)$ \\
Hands & $8(9.5)$ \\
Arms & $7(8.3)$ \\
Throat & $4(4.8)$ \\
Ears & $2(2.4)$ \\
Neck & $2(2.4)$ \\
Feet & $2(2.4)$ \\
Shoulder & $1(1.2)$ \\
Total & $84(100.1)$ \\
\hline
\end{tabular}

Percentages do not add up to 100 due to rounding

squeeze and twist the waist; pressing a baby's mouth forcefully against the breast; being shot in the back; having a window fall on the back; receiving electrical shocks from a cattle prod; and receiving electrical shocks from car wires. The remaining three pain dreams consisted of having a toothache, having a pain under the breast and feeling pain in the abdomen. Three of the 18 reports described very intense pain with words such as "excruciating" or "unbearable". Edited transcripts for nine of the 18 dreams containing references to pain appear in Table 3.

Eight of the 18 pain dreams (44.4\%) involved the subject being chased and/or attacked. Only two of the dreams involved being stabbed and only one involved being shot. These findings contrast with the relatively high frequency of armed violence compiled from the Sleep/Dream Questionnaire responses (16.6\% versus $38.2 \%)$. 
TABLE 3

Edited transcripts of nine pain dreams collected from home dream logs

Subject A (41-year-old female): I'm listening to a colleague and I begin to scratch my left forearm. It's itchy and it burns. I look at my left arm and I see that I have many 'pimples'. I try not to scratch my arm but it's really burning. I think that maybe it's not poison ivy but a really bad allergic reaction. When I woke up I turned on the light to look at my arm.

Subject B (38-year-old male): A young man, unknown to me, confronted me. His nose was very wide - like that of a boxer. He challenged me to hit him with my best shot, then he would do the same to me. Afraid, I refused. If I didn't put him away, he would murder me. After more challenges, and more refusals, I felt his fingers digging deep into both sides of my rib cage. The pain was unbearable. Then I took a long bladed knife and stabbed him between the ribs near his heart. He let go. There was lots of blood.

Subject C (19-year-old female): I hold a tiny premature baby in my hands. It is red, wrinkled and naked. It is screaming so hard that its little face is all contracted and shrivelled up like a Cabbage Patch Kids. I feel quite disgusted and annoyed. I know the only way to make it shut-up is to breast-feed it, so I press its mouth against my nipple, so hard that it hurts me. The baby still wriggles and kicks, so I squeeze it even harder against my breast. My breast hurts but after a while, it stops moving and I enjoy a few minutes of peace. I release my hold but still the baby remains immobile. Curious, I pull it away from me - its face is completely blue and purple, its eyes shut hard, its body limp.

Subject D (28-year-old male): I dreamt that I had been in a train crash. Most people had died and I was stuck in an unknown wooded area. The woods are really thick and I couldn't find a path. A group of 'primitive' people (loin clothes, painted faces) start yelling at me. They grab me and tie me down to the ground with my hands above my head. One of the men takes this long spear with a metal arrow on its end and holds it over my chest. I'm really scared that they're going to kill me. I start to plead with them but then he plunges it into my ribcage and begins to twist it. I scream in pain and beg them to stop. The pain is just excruciating and I try to wiggle around but it doesn't help. The man just keeps on twisting and pushing in further. I can't stand it anymore and beg them to just kill me but they won't. My wife then woke me up saying that I was making moaning and grunting noises. When I woke up I was surprised and relieved to note that the pain, which had been absolutely horrible, had completely disappeared.

Subject E (32-year-old female): I find myself in the house where I grew up when I was a kid. I'm with my dad and it's very nice. This house is no longer ours and I feel as if we were there like thieves. The owners realize that we are there, other people arrive and a big brawl ensues. I escape but I see that I have a hand in my hands (from the fight). It's a women's hand. I try to keep the hand intact so that a doctor can sew it back if we find the person it belongs to. Then, the hand splits itself in half lengthwise. I panic thinking that maybe this is my daughter's hand. I run to the car, but in the dream, I don't know how to drive. The wiring from the accelerator or the brakes unwinds and attacks me. I get out of the car but the wires keep on attacking by giving me electrical shocks. It hurts. The wires keep attacking and they're also crawling on my legs. I woke up still frightened.

Subject F (30-year-old male): I'm in a hotel and I take the elevator to the main floor. Two FBI-type agents and a lady come in and they're talking about a murderer on the 14th floor. I want to see this. The door opens on the 14th floor but everything is quiet. The agents, myself and the lady, who transforms herself into a man, get off the elevator. I then realize that the murderer has left. I take the emergency stairs down to the 13th floor. I see a small woman. She's very pale with red hair. She's standing very stiff. I whisper into her ear "Where is he?" but she can't answer. He is in the room. Then a man with a lab coat approaches me. It's him. He talks to me and knows that I know. There are cadavers on the floor. He takes a liking to me and I try to help him in a way so that he doesn't lose control. Suddenly, he grabs me by the neck and throws me to the floor. He rips out my pubic hair without even taking off my pants. I don't understand how he's doing it but it really hurts. I understand why he's doing it and tell him "You will put them on some girl's vagina to simulate rape". I see the small red-haired lady. She will be his victim. I feel my pubic hair being ripped out - like needles. I wake up.

Subject G (40-year-old female): I have a terrible toothache and I'm lying down on my bed. It's so bad I'm crying. A pleasant, nice young girl comes to console me. She tells me that I should be doing theatre with them. Outside my room there is a theatre troupe that will be performing all day. This young girl tells that I could play my own role and even remain in my bed, or lie down on the stage.

Subject H (34-year-old male): I'm walking down this pretty street in an old European town. A young man approaches me and asks me if I would be interested in buying one of his paintings. He tells me that they look like holograms but that they're made on a regular canvas. He invites me to see them and takes me down this side road that goes behind his house. A group of men step out from behind these wooden stairs. One of them is carrying hot coals in his hands. They tell me that I must hold one of the coals in my hand. Somehow this is all part of the exhibit. I say that I don't really want to but they assure me that it won't hurt. One man grabs a coal and holds it firmly between his hands. He grins and says "See, no problem. Besides, you don't have a choice." I try to close my hand but they just pry my fingers open. Then they put a hot coal in the palm of my hand. It really burns and I yell "No, Stop! Stop!" To my surprise they stop and remove the coal. My hand still hurts and I can see that my skin is burned. The man holding the coals starts looking straight into my eyes and then I woke up. The pain was so intense that I was amazed when I awoke that it existed only in the dream.

Subject I (21-year-old female): I'm hiding from the Gestapo with my family in my closet. We finally manage to escape through a window on the second floor. As I'm climbing out the window, it falls down on my back. I get very scared and my back hurts. I manage to twist myself, open the window again and jump down. I see an SS that spots me so I run as fast as I can towards a wall to hide. I'm hiding and trying to catch my breath. I wonder where the SS is and if I'm going to be safe here. The pain is starting to spread towards my upper back. I wake up with a sore back and it keeps me from falling back to sleep. 
In 16 of the 18 dreams, the pain was described as being localized to a specific area of the body. The most frequently mentioned area was the chest $(\mathrm{n}=5)$, followed by arms/shoulders $(n=2)$, abdomen $(n=2)$, back $(n=2)$, legs $(n=1)$, feet $(\mathrm{n}=1)$, hand $(\mathrm{n}=1)$, teeth $(\mathrm{n}=1)$ and the groin $(\mathrm{n}=1)$.

With respect to affective content, 16 of the 18 pain dreams $(88.9 \%)$ were described as containing only negative affect, whereas two $(11.1 \%)$ were rated as containing both positive and negative emotions. For pain dreams with only negative affect, fear was most commonly cited $(n=8)$, followed by confusion $(n=4)$, frustration $(n=2)$, disgust $(n=1)$ and anger $(n=1)$. The two pain dreams containing both positive and negative emotions began as pleasant dreams and turned into anxiety dreams. In both cases, the dream was described as having become quite unpleasant before any reference to pain was made. Pain intensity was rated on a five-point scale; in 11 of the 18 pain dreams $(61.1 \%)$ the intensity of the negative affect rated 5, in five dreams (27.8\%) intensity rated 4 and in two $(11.1 \%)$ intensity rated 3.

Three of the 16 participants noted in their logs that the pain, which had been intense in what they described as nightmares, had completely disappeared upon awakening (see reports by subjects $\mathrm{D}$ and $\mathrm{H}$ in Table 3 ). Conversely, one participant wrote that she woke up with severe stomach cramps following a dream in which she had experienced prolonged pain in her stomach. Another participant noted that her back pain was still present when she awakened and that it prevented her from falling back to sleep (see report by participant I in Table 3).

Seven of the total sample of 185 participants noted a total of nine dreams in which pain would have been expected (eg, after being shot) and spontaneously indicated that they had been surprised in the dream that no pain had been felt or that they had experienced only an uncomfortable hot flash or mild tingling sensations. Six of these nine dreams were described as containing negative affect, two contained both positive and negative emotions, and one was rated as affectively neutral. Regarding the emotional intensity of the six negative dreams, only one dream was rated (out of 5) as 5; one dream rated as 4 , three as 3 and one as 2 . Numerous other dreams in which pain might have been expected (eg, being stabbed) were reported, but no spontaneous statements about its absence were given.

\section{Pain dreams and physical health}

Six (four women and two men) of the 185 participants reported on the Sleep/Dream Questionnaire that they were currently under the care of a physician for a pain-related condition or that they took prescription or over-the-counter medications for a pain-related ailment. The specific conditions reported were migraines $(n=2)$, back pain $(n=2)$, menses-related abdominal pain $(n=1)$ and arthritis $(n=1)$. Only one of the six reported a pain dream on the dream logs, but the localization of the dream pain (abdomen) was unrelated to her condition (migraines). There was no clear relationship between the content of the 18 pain dreams collected and the physical health of the 16 participants who reported them as assessed by the pain-related items of the SCL-90 and the Sleep/Dream Questionnaire. Three of the 16 participants reporting pain dreams indicated that they had been bothered "quite a bit" or "extremely" by one or more of the painrelated items on the SCL-90. In only one case, however, was there a link between the pain dream reported and the participant's physical health. In this case, the participant reported being bothered "quite a bit" by "pains in the lower back" and had a dream in which she reported experiencing back pains (see report by subject I in Table 3 ).

\section{DISCUSSION}

Results from the retrospective responses to the questionnaire indicate that close to $50 \%$ of individuals report having experienced pain in their dreams at some point in their lives. That the vast majority of these participants had no obvious past history of pain-related conditions suggests that many healthy subjects likely remember having had a dream with pain at least once in their lives. The thematic content of these retrospectively recalled pain dreams (see Table 1) differed from that in the pain dreams collected from home logs. From the retrospective responses, themes of being stabbed or shot were the most frequently reported dreamed actions leading to pain, accounting for approximately $38 \%$ of all pain dreams. Moreover, approximately $80 \%$ of the pain dreams for which a source was specified involved aggressive actions directed towards the subject. By contrast, only three of the 18 pain dreams (17\%) in home logs involved being stabbed or shot, and only half contained aggressive acts directed towards the subject.

There may be at least two reasons for these differences. First, retrospective responses to the questionnaires involved participants' recalling pain dreams that had probably occurred months if not years before the study. It is reasonable to assume that more 'dramatic' pain dreams (eg, dreams in which the person is stabbed, shot or otherwise attacked) are more salient and disturbing than relatively mundane pain dreams (eg, having sore feet or a painful itch), and will, therefore, be more easily remembered over long periods of time. Second, it is possible that for at least some of their retrospectively recalled dreams participants attributed sensations of pain when pain would normally be expected to occur even though no pain sensations had been dreamed. That is, participants may have inferred that pain was present in dreams in which they were shot or stabbed because such actions would result in feelings of pain. The frequent occurrence of spontaneously reported dreams without pain (where it would have been expected) is consistent with this possibility.

Over $80 \%$ of the participants who reported pain dreams on the questionnaire wrote that the pain had been localized to a specific area of the body. A tabulation of these areas of the body (see Table 2) indicates that the distribution of dreamed pain across body parts is likely unrelated to the amount of cortex devoted to the somatosensory representation of these areas (20). Thus, pain in dreams does not appear to result from random activation of the somatosensory cortex. Nor does dreamed pain seem to vary systematically as a function 
of self-reported pain conditions. Thus, the precise psychological and physiological determinants of pain location remain unknown.

Of the 3045 dreams reported in the home dream logs, 16 participants reported a total of 18 dreams that contained references to the subject experiencing pain. These findings indicate that the prevalence of dreams containing pain is very low, occurring once in every 169 dream reports and in one of every 12 subjects. Nevertheless, in a majority of cases where pain occurs, it is integrated into the dream narrative; specific episodes of pain typically result from sudden and/or violent encounters with other characters or objects. Pain sensations, however, do not appear to be an inevitable consequence of such encounters or of expectations about feeling pain. For instance, one participant in the present study reported a dream in which someone used a blade to cut the palm of his hand but he "was surprised that it didn't hurt at all - all there was some cringing of the skin and then a feeling of warmth where the cut had been made". Another participant reported a dream in which he was hit directly in the head by a fast moving baseball. He wrote that "I remember thinking 'I've just been hit by a baseball, so my head should hurt' but I didn't feel any pain".

The types of pain reported in the home logs are quite diverse and are not restricted to one area of the body. As with the pain dreams reported on the questionnaire, most pain dreams collected from home logs describe a specific area of the body where the pain had been localized. However, the frequency distribution for body areas in the sample of home dreams differs from that in the questionnaires. For example, pain in the chest area was reported in $28 \%$ of home pain dreams and in only $6 \%$ of the pain dreams reported on the questionnaire. Conversely, the most frequently cited areas for dream pain reported on the questionnaire (ie, abdomen, legs, and head or face) were rarely cited in the home pain dreams. The relatively small sample size of home pain dreams and the fact that home dreams were recorded upon awakening while the dreams collected on the questionnaire were reported long after their occurrence, may account, in part, for these differences. Over long periods of time, memory of pain localization may be less accurate than memory of the presence or absence of pain.

All of the 18 home pain dreams were described as containing negative affect; two also contained positive emotions. In our previous study of the association of pain dreams to pressure stimulation of the legs (6), almost half of the pain dreams collected contained strong negative affect. Anger, the most frequently cited emotion, occurred in five of 13 reports $(38.5 \%)$. By contrast, fear was the most commonly cited emotion in the home pain dreams, while only one pain dream contained anger. This difference may result from the conditions under which the pain dreams occurred. In the home dreams, pain occurred for reasons that were generally beyond the subject's perceived control and the emotions reported (eg, fear, confusion or frustration) were appropriate for the dream's content. In the laboratory dreams, six of the 13 reports contained direct references to the stimulating pressure cuff and half made references to the experimenter of the study; in all but one, pain was localized in the subject's legs. One may infer from these observations that, in at least some of the laboratory dreams, participants specifically associated their experiences of pain with the fact that they were participating in an experiment in the sleep laboratory. In other words "anger may have been produced...because the pain source was both known to and potentially controllable by subjects" (6).

In the present study, three participants reported in their logs that the intense sensations of pain present in their dreams had completely disappeared upon awakening from the dream (see reports by subjects $\mathrm{D}$ and $\mathrm{H}$ in Table 3 ). Similar findings were noted in two laboratory studies that found that unambiguous pain dreams can occur during nonstimulated REM periods $(6,7)$. These observations suggest that the cognitive systems that contribute to the representation of pain imagery are sometimes functional during dreaming and that actual painful stimuli need not be present for pain sensations to occur in laboratory or home dreams. Similarly, such examples illustrate that arguments that nociception (ie, neuronal activity in the pain-mediating nervous system) is neither a necessary nor sufficient condition for the subjective experience of pain (eg, 21), apply to dreaming as well as waking states.

The lack of data on the relationship between the content of pain dreams and physical health precludes us from drawing firm conclusions on this topic. Results from the dream logs, however, indicate that pain dreams can be experienced by healthy individuals. In only one case were the pain sensations in a dream (ie, lower back pain that spread towards the upper back) associated with a waking pain-related condition (ie, frequent back pains). Interestingly, this participant (see report by I in Table 3) noted that the back pain in her dream was still present when she awakened. This suggests that real pain sensations may influence the process of dream construction. A study is currently underway in our research group to examine such processes in the dreams of individuals with chronic or acute pain.

The present findings indicate that unambiguous references to pain sensations occur in approximately one of every 170 home dreams. However, this may be an underestimate of the true prevalence. First, the reports came from a study on the relation between dream content and well-being - the participants were not aware of our interest in pain dreams. Furthermore, participants did not receive any instructions about noting particular physical sensations in their dreams, and the pain-related questions that appeared on the questionnaires were imbedded in a large questionnaire battery. Thus, the participants were not sensitized to reporting pain sensations in their dream logs, and some participants may not have reported them. Such dreams would not have been scored as pain dreams given our strict criteria for scoring unambiguous references to pain as experienced by the dreamer.

Second, our sample comprised individuals who were very interested in dreams and whose rates of dream recall were approximately three times that of the general population (22). How well these findings generalize to the general population remains to be determined. 
Our results on the prevalence of pain sensations in dreams add to information from other studies that have reported on the occurrence of other sensory modalities (eg, auditory, gustatory, olfactory and kinesthetic sensations) in laboratory and home dream reports (eg, 16,23,24). However, to our knowledge, no model or theory has been proposed to explain how sensory experiences such as pain can be produced in the dream state in the absence of external stimuli.

One possibility is that self-experience during dreaming is governed by a mechanism similar to the 'neuromatrix' postulated by Melzack (25) to govern bodily experience while awake. The function of the neuromatrix is revealed by the occurrence of phantom body parts (limbs, breasts, genitals, bladders, etc) following surgical removal or denervation of the actual body part (eg, 26-28). The intense reality of phantom body parts presumably stems from a brain process that underlies the experience of the body when it is intact. Similarly, during dreaming these brain processes may be acti-

\section{REFERENCES}

1. Moldofsky H. Sleep and musculoskeletal pain. In: Vœrøy H, Merskey H, eds. Progress in Fibromyalgia and Myofacial Pain. Amsterdam: Elsevier Science Publishers, 1993:137-48.

2. Seafield F. The Literature and Curiosities of Dreams. London: Lockwood, 1869.

3. MacFarlane A. Dreaming. 3 parts. Edinb Med J 1890;36:712-9.

4. Saint-Denys H. Dreams and How to Guide Them. London: Duckworth, 1982 [orig 1867].

5. Freud S. The Interpretation of Dreams. New York: Basic Books, 1953 [orig 1900].

6. Nielsen TA, McGregor DL, Zadra A, Ilnicki D, Ouellet L. Pain in dreams. Sleep 1993;16:490-8.

7. Zadra AL, Nielsen TA, Lavigne G, Germain A. Pain in stimulated and nonstimulated laboratory dreams. Sleep Res 1996;25:149.

8. Kardiner A. The Traumatic Neuroses of War. New York: Hoeber, 1941.

9. Levitan HL. The significance of certain catastrophic dreams. Psychother Psychosom 1976;27:1-7.

10. Levitan HL. The significance of certain dreams reported by psychosomatic patients. Psychother Psychosom 1978;30:137-49.

11. Levitan HL. The dream in traumatic states. In: Natterson J, ed. The Dream in Clinical Practice. New York: Jason Aronson, 1980:271-81.

12. Levitan HL. Traumatic events in dreams of psychosomatic patients. Psychother Psychosom 1980;33:226-32.

13. Calkins M. Statistics of dreams. Am J Psychol 1893;5:311-43.

14. Hall CS, Van de Castle RL. The Content Analysis of Dreams. New York: Appleton Century Crofts, 1966.

15. Snyder F. The phenomenology of dreaming. In: Madow H, Snow L, eds. The Psychodynamic Implications of the Physiological Studies on Dreams. Springfield: Charles Thomas, 1970:124-51.

16. McCarley RW, Hobson JA. The form of dreams and the biology of vated and thus produce a variety of realistic sensations including pain. Thus, in dreams we typically experience a sense of self (or a 'phantom body') that sometimes includes vivid kinesthetic sensations and occasionally any of a myriad of sensory experiences (eg, from orgasm to pain), affective states and cognitive elements such as language, memory and self-reflectiveness. Melzack's model, as applied to dreams, also accounts for how erotic dreams with orgasm are sometimes reported by quadriplegics with a complete spinal break (29). Thus, pain and other intense sensory experiences may for some individuals become encoded in the neuromatrix in such a way that they will, when circumstances permit, be reproduced in imaginal form during dreaming states.

ACKNOWLEDGEMENTS: This research was supported by the Medical Research Council of Canada and by the Social Sciences and Humanities Research Council of Canada.

sleep. In: Wolman BB, ed. Handbook of Dreams: Research Theory and Applications. New York: Van Nostrand Reinhold, 1979:76-130.

17. Zadra AL, Nielsen TA, Assaad JM, Donderi DC. The prevalence of pain in dreams. Sleep Res 1995;24A:261.

18. Brown RJ, Donderi DC. Dream content and self-reported well-being among recurrent dreamers, past recurrent dreamers, and nonrecurrent dreamers. J Pers Soc Psychol 1986;50:612-23.

19. Derogatis L. Manual for the SCL-90 Revised Version. Baltimore: L Derogatis, 1977.

20. Penfield W, Rasmussen T. Cerebral Cortex of Man: A Clinical Study of Localization of Function. New York: Macmillan, 1968.

21. Bromm B. Consciousness, pain, and cortical activity. In: Bromm B, Desmedt JE, eds. Pain and the Brain: From Nociception to Cognition. New York: Raven Press, 1995:35-59.

22. Webb WB, Kersey J. Recall of dreams and the probability of stage 1 REM sleep. Percept Mot Skills 1967;24:627-30.

23. Trotter K, Dallas K, Verdone P. Olfactory stimuli and their effects on REM dreams. Psychiatr J Univ Ottawa 1988;13:94-6.

24. Zadra AL, Nielsen TA, Deakos M. The prevalence of auditory, olfactory, gustatory and pain experiences in 1437 home dreams. Association for the Study of Dreams 13th Conference, Berkeley, California, July 1996, 1996:237-9. (Abst)

25. Melzack R. Phantom limbs, the self and the brain. Can Psychol 1989;30:1-16.

26. Heusner AP. Phantom genitalia. Trans Am Neurol Assoc 1950;75:128-31.

27. Dorpat TL. Phantom sensations of internal organs. Comp Psychiatry 1971;12:27-35.

28. Wynn-Parry CB. Pain in avulsion lesions of the brachial plexus. Pain 1980;9:41-53.

29. Money J. Phantom orgasm in the dreams of paraplegic men and women. Arch Gen Psychiatry 1960;3:373-82. 


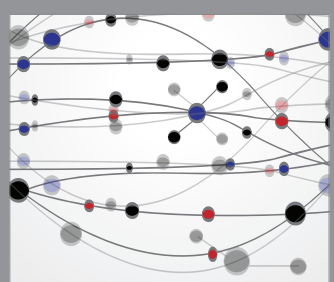

The Scientific World Journal
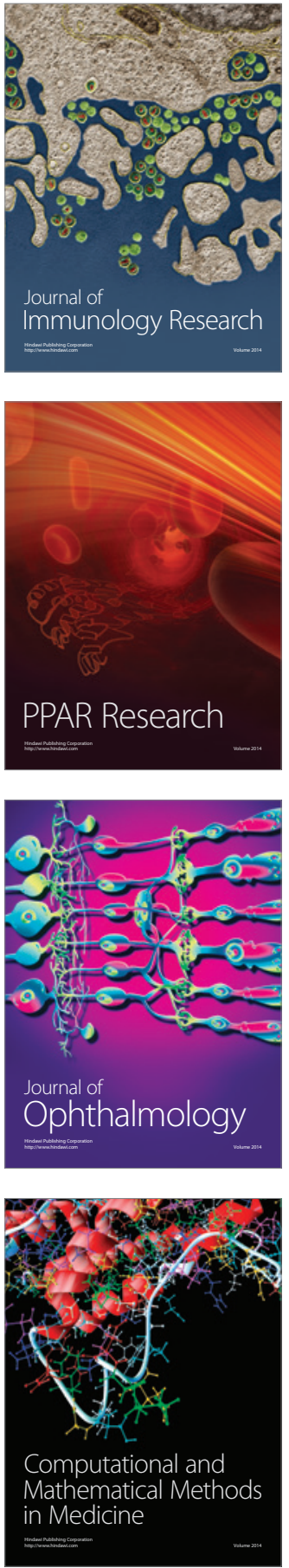

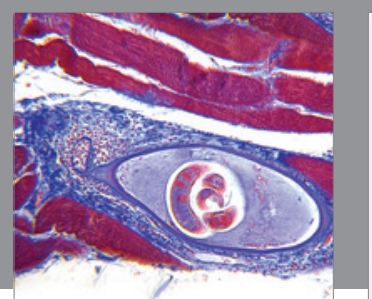

Gastroenterology Research and Practice

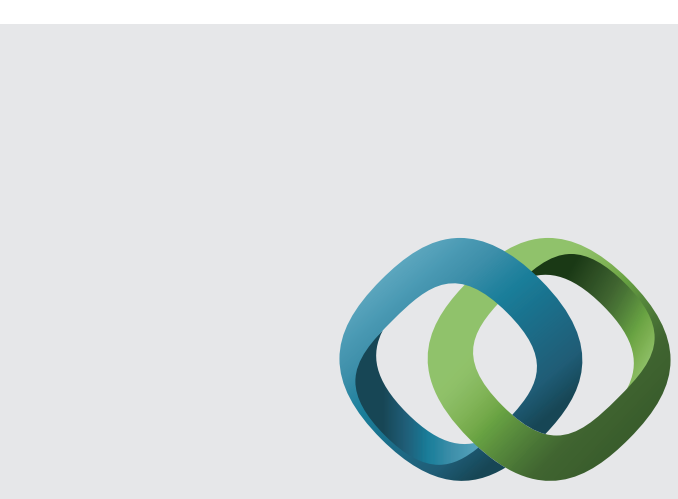

\section{Hindawi}

Submit your manuscripts at

http://www.hindawi.com
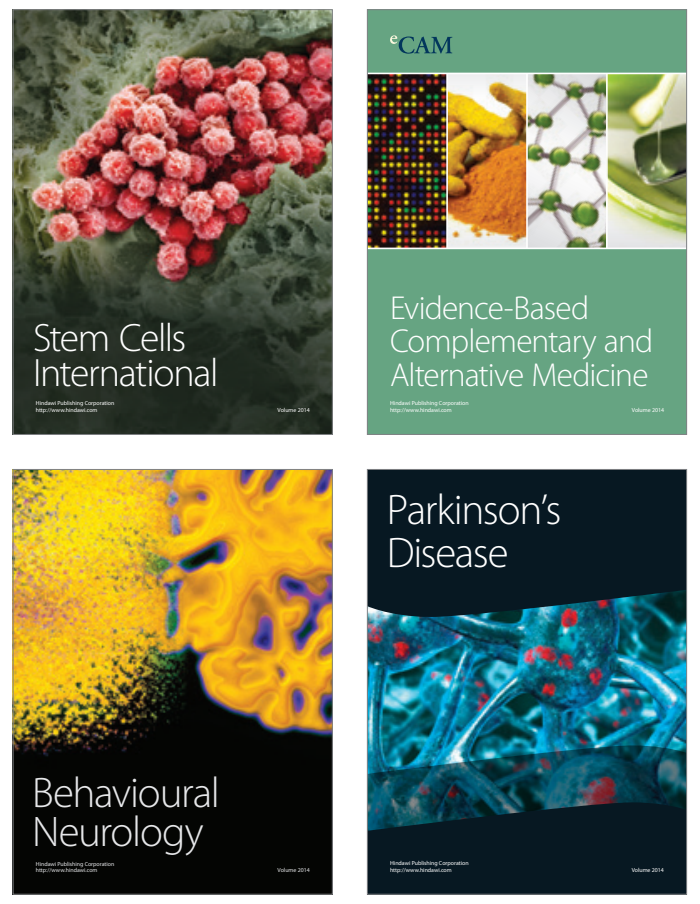
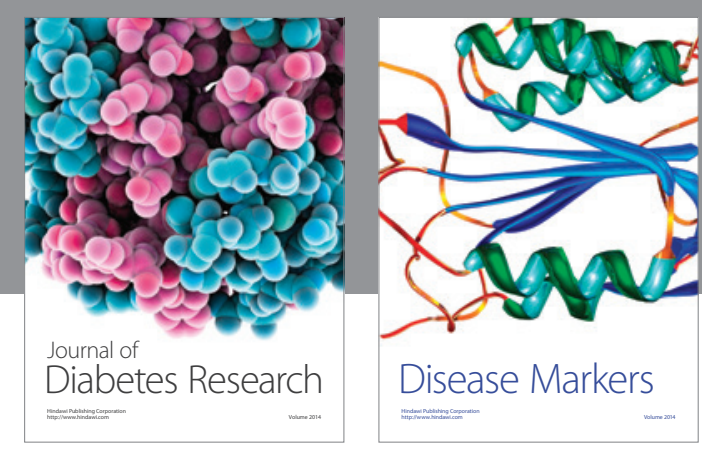

Disease Markers
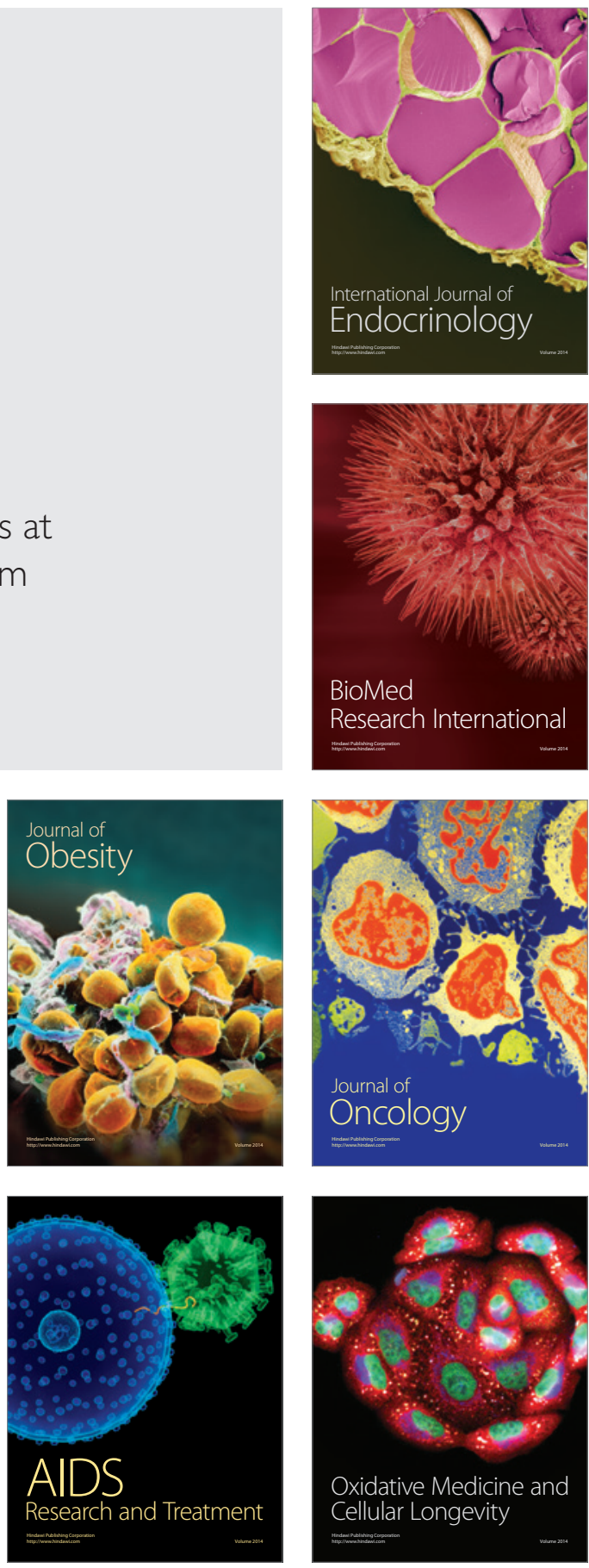